\title{
Predicting Efficacy and Toxicity in the Era of Targeted Therapy: Focus on Anti- EGFR and Anti-VEGF Molecules
}

\author{
Michele Caraglia $^{1 \S}$, Daniele Santini ${ }^{2 \S}$, Giuseppe Bronte ${ }^{3}$, Sergio Rizzo $^{3}$, Giovanni Sortino ${ }^{3}$, Giovam Battista \\ Rini $^{4}$, Gaetana Di Fede ${ }^{3, *}$ and Antonio Russo ${ }^{3}$
}

\begin{abstract}
${ }^{I}$ Experimental Pharmacology Unit, National Institute of Tumours, Fondazione “G. Pascale”, Naples, Italy, ${ }^{2}$ Medical Oncology, University Campus Bio-Medico, Rome, Italy, ${ }^{3}$ Section of Medical Oncology, Department of Surgical and Oncological Sciences, Università di Palermo, Palermo, Italy, ${ }^{4}$ Dipartimento di Medicina Interna e Specialistica DIMIS, Universitá di Palermo, Italy

Abstract: The treatment of solid malignancies includes various target drugs, such as monoclonal antibodies and tyrosine kinase inhibitors, which exert their effect alone or in combination with chemotherapy. The main part of these molecules have a target on proteins of EGFR and VEGF pathways. The particular toxicity profile and the financial impact, deriving from the application of these agents in cancer treatment, prompted a lot of researches to define predictive factors of their efficacy. Various biomarker were identified among the components of the targeted pathways. However just few studies allowed to identify specific factors to predict the toxicity of these drugs. In this review EGFR and VEGF-related pathways are described, most relevant clinical findings about target therapy applications are exposed and the clinical impact of predictive factors of efficacy and toxicity are discussed.
\end{abstract}

Keywords: VEGF, EGFR, predictive factors, toxicity, target therapy.

\section{INTRODUCTION}

The treatment of the most prevalent solid tumors is now based on the combination of chemotherapy with biological drugs. EGFR and VEGF showed to exert a relevant role in the development and drug sensitivity of these malignancies. Various molecules were produced to target the EGFR- and VEGF-related pathways.

The efficacy of these molecules seems dependent on biomarkers, which could be detected through various techniques of molecular biology. Besides, for these agents we know a toxicity profile, which is different from that we have long managed with chemotherapy.

\subsection{EGFR Pathway}

The family of epidermal growth factor receptor (EGFR) is involved in various pathways of cell function including development, metabolism and other biological phenomena.

The binding of specific cognate ligands (EGF, transforming growth factor- $\alpha$, amphiregulin) triggers the homodimerization of two EGFRs or the heterodimerization of EGFR with other family members [1]. The tyrosine kinase (TK) activition is exploited by the intracellular domain of EGFR by its autophosphorylation. The phosphotyrosine residues act as a docking site for various adapter molecules. Various intracellular pathways, including RAS/RAF/ MAPK and PI3K/Akt are subsequently activated [2]. RAS protein function is normally regulated by cycling between inactive GDPbound and active GTP-bound forms. Signaling is terminated when RAS-GTP is hydrolyzed to the RAS-GDP inactive complex by GTPase-activating proteins (GAPs) [3]. Activated RAS recruits Raf protein to the cell membrane and phosphorylates it, triggering serine-threonine kinase activity of various proteins. Finally active mitogen-activated protein kinases (MAPKs) can translocate to the nucleus, where they regulate the activity of several transcription factors for the expression of multiple genes of survival and proliferation [4-6] (Fig. 1).

*Address correspondence to this author at the Section of Medical Oncology, Department of Surgical and Oncological Sciences, Università di Palermo, Via del Vespro 129, 90127 Palermo, Italy; Tel: +39-091-6552500;

Fax: +39-091-6554529; E-mail: gaet.difede@ unipa.it

${ }^{\S}$ These authors contributed equally to this work.

\subsection{VEGF Pathway}

The VEGF pathway plays critical roles in tumor growth by diverse mechanisms. Although VEGF is actually a family of at least 7 members [VEGF-A, -B, -C, -D, and -E, and placental growth factor, (PlGF) -1 and -2], the term EGF typically refers to the VEGF-A isoform, one of the most studied members and a major mediator of tumor angiogenesis. VEGF-A is a proangiogenic factor that plays important roles in cell migration, proliferation, and survival. Alternative splicing yields at least six isoforms of VEGF-A, existing of 121, 145, 165, 183, 189 and 206 amino acid residues [79], which differ in their incorporation of exons that determine the degree of cell surface and extracellular matrix association. The VEGF165 is the most predominant form. Among VEGF family members, VEGF and PIGF have been well characterized as modulators of angiogenesis in many tumors [10,11]. These growth factors bind to VEGF receptors on endothelial cells and promote their proliferation, survival, migration, and tube formation. VEGF binds to VEGFR1, VEGFR2, and neuropilins (NRP), whereas PIGF only binds VEGFR1 and NRP-1 and NRP-2 [12]. A third receptor, VEGFR-3, is involved in lymphangiogenesis and does not bind VEGF-A. Knockout of VEGF, VEGFR1, VEGFR2, or both NRP-1 and NRP-2 induces embryonic lethality, whereas PlGF deficiency impairs pathologic angiogenesis by attenuating the response to VEGF [10-13]. VEGF binds with higher affinity to VEGFR1 than to VEGFR2, but the latter has stronger tyrosine kinase activity and is widely assumed as the mediator of the pro-angiogenic activities of VEGF [10,11]. Surprisingly, unlike VEGFR1 deficiency, deletion of the tyrosine kinase domain of VEGFR1 (in $f l t 1^{\mathrm{TK}-J}$ mice) does not lead to embryonic lethality or vascular phenotypes, suggesting that VEGFR1 acts as a "decoy" for pro-angiogenic factors during development [14]. Nevertheless, VEGFR1 and VEGFR2 could crosstalk inter- and intramolecularly [15]. VEGF binds to the VEGFR, that is a Receptor Tyrosine Kinase, leading to receptor dimerization and subsequent auto phosphorylation of the receptor complex. The phosphorylated receptor then interacts with a variety of cytoplasmic signaling molecules, leading to signal transduction and eventually angiogenesis [16]. The classical ras $\rightarrow$ Erk and $\mathrm{PI} 3 \mathrm{~K} \rightarrow$ Akt-depednent pathways are involved in the signalling activated by VEGF-VEGFR network thus leading to the proliferation and survival of endothelial progenitors (Figs. 2 and $\mathbf{3}$ ). 


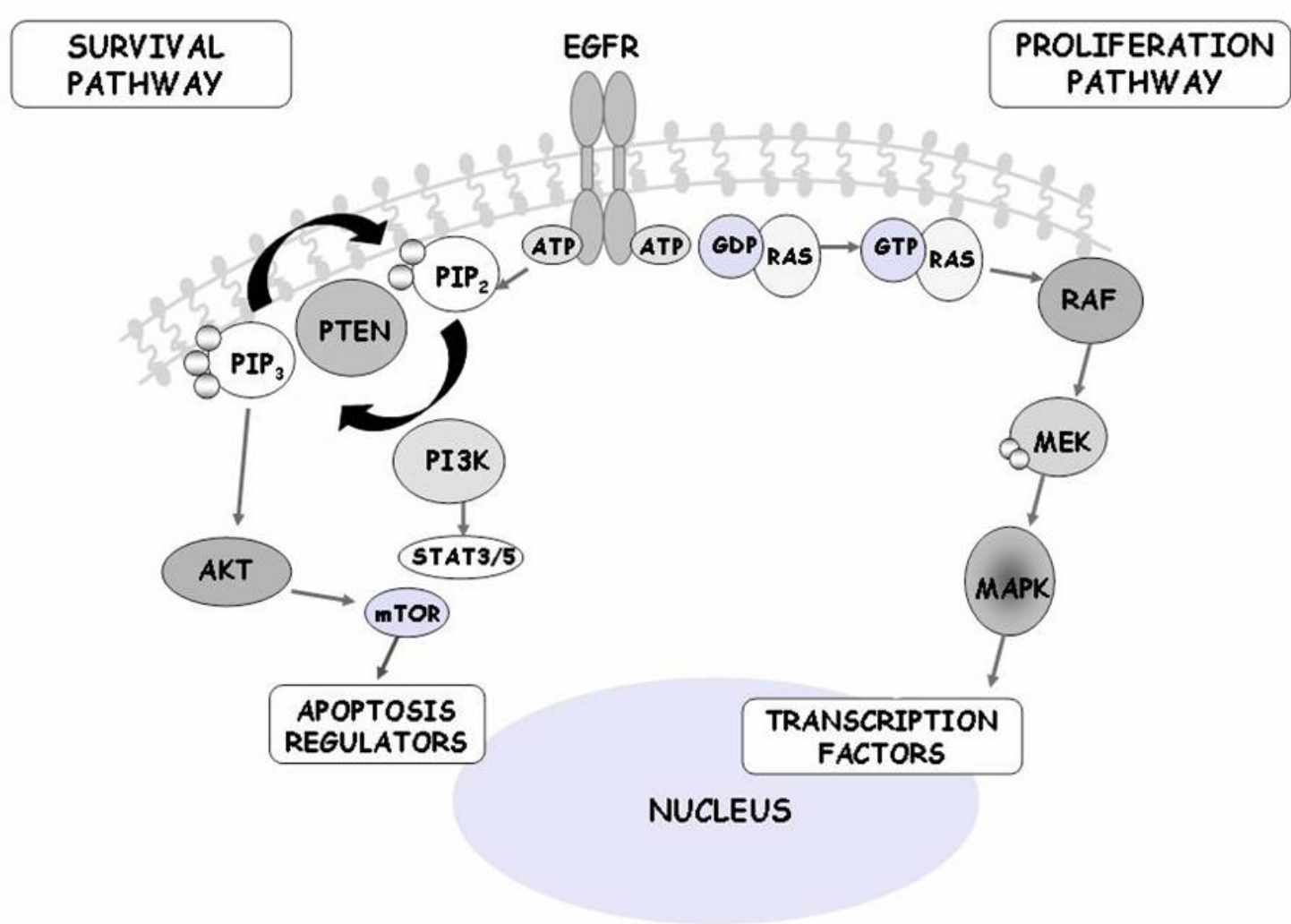

Fig. (1). EGFR-related pathways

EGFR activation, by ligand binding or mutation in the TK domain, triggers two main pathways, which regulate survival and proliferation in the cell function. The RAS/RAF/MAPK pathway induces transcription factors in the nucleus. The expression of proliferation genes is enhanced. The PI3K/Akt pathway modulates the function of apoptosis regulators. The cell survival results prolonged.

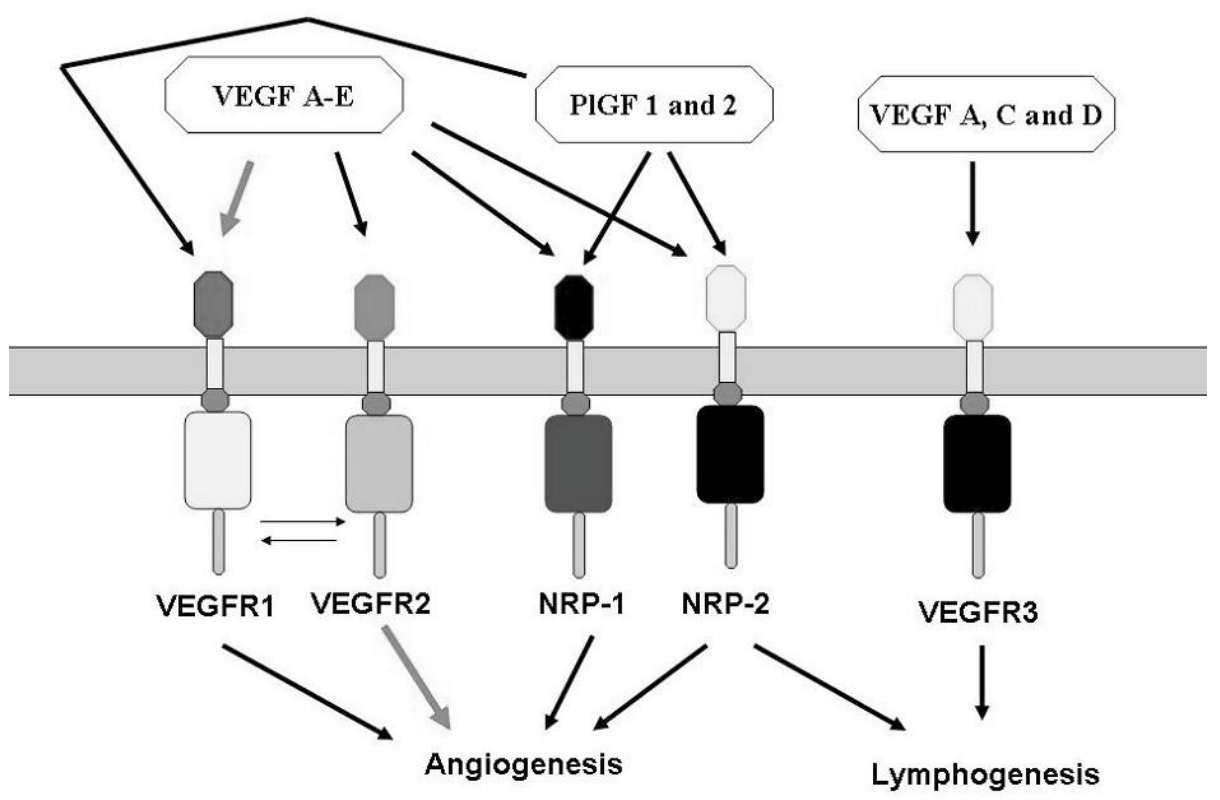

Fig. (2). VEGF, PIGF and their receptors

VEGF A-E bind prevalently to VEGFR1 and with less affinity to VEGFR2, but the latter has hifigher tyrosine kinase acticity and is prevalently involved in tunmour neo-angiogenesis. However, the two receptors strongly cross talk through heterodimerization. VEGFA-E bind also NRP-1 and NRP-2 while PIGF-1 and 2 bind VEGFR1 and NRP-1 and 2. NRP-1 is involved in angiogenesis while NRP-2 also in lymphogenesis. VEGF A, C and D bind also VEGFR3 that is, in turn, involved exclusively in lymphogenesis. 


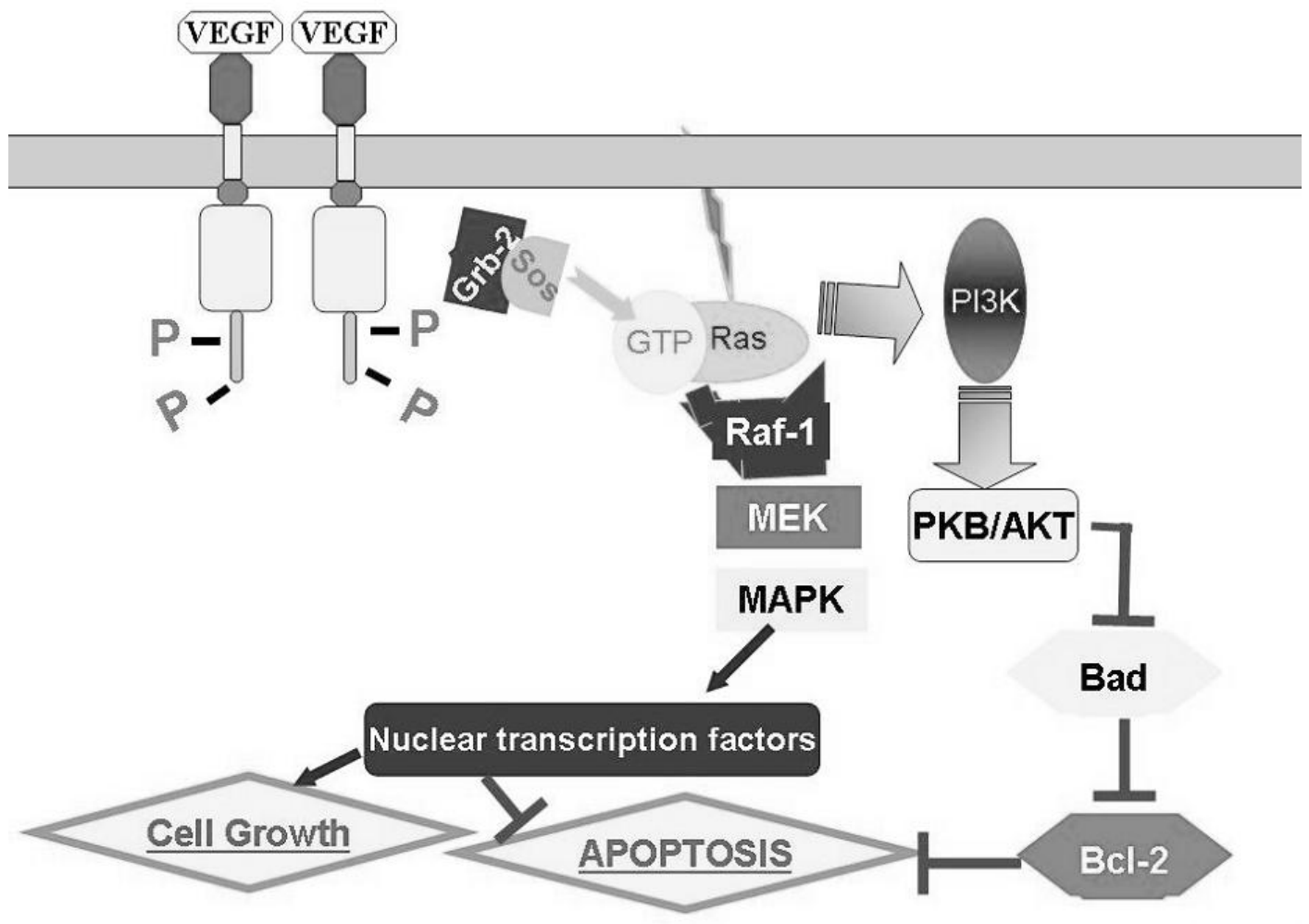

Fig. (3). VEGF-induced signalling

VEGF binds its receptors that, in turn, heterodimerize or homodimerize. After the dimerization the cytoplasmic tails of the receptors are phosphorylated in Tyrosine residues that, in turn, recruit cytoplasmic factors including nucleotide exchanging factors such as Sos that once placed on the inner side of the plasma membrane activate for co-localization ras that can trigger the mitogen activated protein kinase (MAPK) cascade leading to survival and proliferation signals. Alternatively, ras can also activate the $\mathrm{PI} 3 \mathrm{~K} \rightarrow$ Akt signalling leading to survival signals through the activation of anti-apoptotic proteins such as Bcl-2.

\section{ANTI-EGFR AND ANTI-VEGF MOLECULES}

\subsection{Anti-EGFR Monoclonal Antibodies}

Two anti-EGFR monoclonal antibodies are currently available for the treatment of mCRC. Cetuximab is a chimeric immunoglobulin G1 antibody, and panitumumab is a fully human immunoglobulin G2 antibody. First cetuximab was studied for the treatment of patients with chemo-refractory advanced colorectal cancer. In particular cetuximab combined with irinotecan achieved higher response rate rather than cetuximab alone in a randomized phase II trial in patients resistant to irinotecan $(22.9 \%$ versus $10.8 \%$, $\mathrm{p}=0.007$ ) [17]. Median PFS and response rate were also improved by the same combination of cetuximab and irinotecan when compared to irinotecan alone (PFS: 4.0 vs 2.6 months, $\mathrm{p} \leq 0.0001$; RR: $16.4 \%$ vs $4.2 \%, \mathrm{p}<0.0001$ ), even if not statistically significant difference was observed for the median OS (10.7 versus 10.0 months, $\mathrm{p}=0.71$, which was the primary endpoint of this study [18]. However this result may be a consequence of the crossover to cetuximab, which a large number of patients in the control arm experienced. Cetuximab showed benefit also when it was administered alone as compared to best supportive care in chemotherapy refractory patients. In this study the median OS was 6.1 months for cetuximab and 4.6 months for best supportive care $(p=0.005)$ [19]. More recently an advantage for the use of cetuximab in the first-line treatment was demonstrated. The addition of cetuximab to FOLFIRI versus FOLFIRI alone in the CRYSTAL trial resulted in a modest but statistically significant increase in the median PFS ( 8.9 vs 8.0 months, $p=0.048$ ) [20]. In the large randomized phase II study for chemonaïve patients with metastatic colorectal cancer, they were treated with either FOLFOX plus cetuximab or FOLFOX alone. No statistically significant differences in median PFS (7.2 months in both arms) and response rate (46\% vs $36 \%, \mathrm{p}=0.064)$ were observed [21]. Anyway a significantly wider difference for RR was achieved in subjects with good performance status (49\% vs $37 \%, \mathrm{p}=0.032$ ). A phase III trial evaluated single agent panitumumab versus best supportive care (BSC) in the patients with chemorefractory $(100 \%$ and $37 \%$ of the patients had received 2 and 3 lines of previous treatment, respectively) advanced colorectal cancer, which expressed EGFR regardless the KRAS mutational status. Panitumumab reduced the risk of disease progression with respect to BSC alone by almost half (hazard ratio $=0.54,95 \% \mathrm{CI}$ : $0.44-0.66, p<0.0001)$ [22]. The group of patients bearing a KRAS mutation achieved no clinical responses when treated with panitumumab, whereas those with wild-type KRAS achieved a 17\% ORR, because of the treatment with panitumumab [23]. It is interesting that among patients in the control arm who crossed over to receive panitumumab after progression, RR was $11 \%$ with an additional $33 \%$ of patients achieving SD [24].

\subsection{Anti-EGFR Tyrosin Kinase Inhibitors}

Gefitinib (ZD1839, Iressa) and erlotinib (OSI-774, Tarceva) are two small molecules approved for the treatment of non-small-cell lung cancer (NSCLC). These two drugs disrupt EGFR signaling by competing with adenosine triphosphate (ATP) for the binding sites at tyrosine kinase domain. So they inhibit the phosphorylation and activation of EGFRs and the downstream signaling network. Both agents can induce dramatic clinical response in patients who fail chemotherapy. The first is indicated in patients affected by advanced or metastatic NSCLC with activating mutations on the tyrosine Kinase domain of EGFR. Those mutations occurr in $10-15 \%$ of NSCLC in European countries and $30-40 \%$ in Asian population $[25,26]$. The IPASS study evaluated gefitinib oral monotherapy vs doublet chemotherapy (carboplatin/paclitaxel) as first line treatment of Asian patients with NSCLC, which were highly selected for 
adenocarcinoma histology, good performance status, non-smoker or light smoker status. The primary end point was progression-free survival (PFS) and the secondary were objective response rate, overall survival, quality of life, disease-related symptoms, safety and tolerability. 1217 treatment-naïve patients with adenocarcinoma were involved. The first analysis in 2008 showed that gefitinib was superior to chemotherapy in terms of PFS in the overall population (HR $0.74,95 \%$ CI $0.65-0.85, \mathrm{p}<0.001$ ) [27]. Subsequently this superiority of gefitinib vs chemotherapy in the overall population was showed to be restricted to the subgroup of EGFR mutation-positive patients. In these patients the risk for progression halved with gefitinib compared with carboplatin/paclitaxel, (HR=0.48, 95\% CI 0.36$0.64, \mathrm{p}<0.001)$ and median progression-free survival increased from 6.3 to 9.5 months. Gefitinib also achieved significant benefits in objective response rate, quality of life and symptom improvement compared with carboplatin/paclitaxel in EGFR mutation-positive patients [28]. In the overall population, unselected for clinical or molecular factors, gefitinib and chemotherapy showed no significant differences in OS $(\mathrm{HR}=0.90,95 \%$ CI $0.79-1.02, \mathrm{p}=0.11$, median OS 18.8 vs. 17.4 months). Neither was there a significant difference between treatment arms for OS in the subgroups defined by EGFR mutation status: EGFR mutation-positive patients ( $\mathrm{HR}=1.00$, 95\% CI 0.76-1.33, median OS 21.6 vs. 21.9 months); EGFR mutation-negative patients $(\mathrm{HR}=1.18,95 \%$ CI $0.86-1.63$, median OS 11.2 vs.12.7 months); and patients whose EGFR mutation status was unknown (HR=0.82,95\% CI 0.70-0.96, median OS 18.9 vs. 17.2 months) [29]. Erlotinib has been approved for the treatment of locally advanced or metastatic non-small cell lung cancer that is refractory to at least one prior chemotherapy regimen and in combination with gemcitabine for the first-line treatment of locally advanced, unresectable or metastatic pancreatic cancer. Erlotinib was evaluated in the large phase III BR.21 trial for second and third-line therapy of advanced NSCLC. It showed a significant advantage in terms of OS, TTP and quality of life (QoL). These findings led to FDA approval [30]. The use of erlotinib versus placebo as maintenance treatment in advanced non-small-cell lung cancer has been evaluated in the double-blind, randomized, phase III SATURN trial. Patients, without disease progression after 4 cycles of chemotherapy, showed benefit in response rates and disease control rates. Median PFS was significantly longer with erlotinib than with placebo (HR for progression $0.71,95 \%$ CI 0.62 $0.82 ; \mathrm{p}<0.0001)$ [31].

\subsection{Anti-VEGF Molecules}

Results obtained from preclinical studies indicated that antiangiogenic agents induced tumor stabilization or even regression in subcutaneous tumor models. As the suboptimal character of subcutaneous tumors for the purpose of studying anti-angiogenic therapy was not recognized at that time, these findings led to the assumption that also in the clinic anti-angiogenic therapy could turn cancer into a chronic disease. This resulted in numerous clinical trials evaluating the beneficial effects of different anti-angiogenic agents. As stated above angiogenesis is tightly regulated through a complex interplay of pro- and anti-angiogenic factors. Apart from targeting pathways that promote angiogenesis, increasing the amount of antiangiogenic factors is another approach to inhibit tumor growth by blocking angiogenesis.

\subsubsection{Bevacizumab}

Bevacizumab is a humanized monoclonal antibody that binds to VEGF-A, preventing it from binding to receptors and activating signaling cascades that lead to angiogenesis. Initial proof of the concept that targeting VEGF-A could inhibit the growth of tumors (despite its having no effect on the growth rate of the tumor cells in vitro) was demonstrated in a mouse model in 1993 using a monoclonal antibody against VEGF-A, [32] leading to the clinical development of bevacizumab. Initial clinical trials in patients with colorectal cancer tested irinotecan, fluorouracil (5-FU), and leucovorin with or without bevacizumab [33]. The addition of bevacizumab significantly increased the progression-free survival (PFS), as well as the median overall survival (OS) leading to FDA approval of bevacizumab as the first drug developed solely for antiangiogenesis anticancer use in humans. The anticancer activity of bevacizumab across all tumor types has demonstrated some mixed results. Bevacizumab did not provide any benefit with regard to PFS or OS for patients with metastatic breast cancer when used in combination with capecitabine [34]. Further studies in a phase 3 trial of patients with previously untreated metastatic breast cancer using paclitaxel with or without bevacizumab demonstrated that the addition of bevacizumab increased PFS (11.8 months vs 5.9 months without bevacizumab) and increased the overall response rates $(36.9 \%$ vs $21.2 \%$ without bevacizumab) [35]. However, there was still no significant increase noted in OS, as had been observed previously with colorectal cancer and NSCLC [33, 36, 37]. A beneficial response may be masked by the lack of biomarker screening in patients in many of the clinical trials, because bevacizumab is specific for VEGF. By screening for tumors that overexpress VEGF and/or are highly dependent on VEGF signaling, the likelihood of a positive response to bevacizumab would most likely be increased. Targeted therapies may prove more effective when patients are screened for markers, ensuring that the proper subset of the population is treated with a particular targeted drug. Bevacizumab is currently being tested in several hundred clinical trials in a variety of different tumor types and as of 2009, bevacizumab was approved for various indications in colorectal cancer, NSCLC, breast cancer, renal cell carcinoma (RCC), and glioblastoma (see the Database of Current Clinical Trials at www.clinicaltrials.gov).

\subsubsection{Aflibercept (VEGF-Trap)}

Aflibercept (VEGF-Trap, AVE0005) is a soluble fusion protein of the human extracellular domains of VEGFR-1 and VEGFR-2 and the Fc portion of human immunoglobulin (Ig) G. Aflibercept binds to both VEGF-A and PIGF with a higher affinity than monoclonal antibodies and essentially renders the VEGF-A and PIGF ligands unable to bind and activate cell receptors [38]. Aflibercept was engineered to optimize pharmacokinetic properties while still maintaining the potent VEGF blocking activity compared with that demonstrated by other anti-VEGF antibodies. In vitro, aflibercept demonstrated significant antiproliferative activity and completely blocked VEGF-induced VEGFR-2 phosphorylation when added in a 1.5-M excess of VEGF. Aflibercept inhibited tumor growth in xenograft models and blocked nearly all tumor-associated angiogenesis, resulting in tumors that appeared nearly avascular. Aflibercept is currently in clinical trials, with some early results reported. In phase 2 trials in which it was used as a single agent in patients with ovarian cancer, $41 \%$ of patients had stable disease at 14 weeks. In addition, a reduction of $30 \%$ or more in tumor size was noted in $8 \%$ of patients [39]. Another phase 2 trial of aflibercept in 33 patients with NSCLC demonstrated 2 partial responses; to our knowledge, interim analysis results are not yet available [40]. In contrast, a phase 2 trial of aflibercept in patients with metastatic breast cancer demonstrated a response rate of $5 \%$ and the PFS rate at 6 months was $10 \%$, rates that did not meet efficacy goals and were determined to be too low to continue [41]. Additional clinical trials of aflibercept are currently ongoing in a variety of malignancies including prostate cancer, colorectal cancer, ovarian cancer, thyroid cancer, RCC, and brain cancer.

\section{PREDICTIVE FACTORS OF EFFICACY}

\subsection{EGFR-Related Predictive Factors}

\subsubsection{EGFR Overexpression}

Several studies investigated the expression levels of EGFR protein and its link with cancer prognosis, in many types of cancers. Despite conflicting results were reported, those malignant tumors which overexpress EGFR protein are associated with a poor prognosis. EGFR is estimated to be overexpressed in $60-85 \%$ of colo- 
rectal cancers (CRC), and it seems to be correlated with a higher stage, aggressiveness, presence of metastases and poorer prognosis [42]. The relationship between the levels of EGFR protein expression, as determined by immunohistochemistry, and sensitivity to anti-EGFR antibodies, has been evaluated in many clinical trials, but the results showed a lack of association between EGFR detection and response to EGFR-targeted treatment. In fact, objective responses have been observed in patients with low or high EGFR level expression: it cannot be considered as an inclusion criterion for patients undergoing treatment with anti-EGFR mAbs [43].

\subsubsection{EGFR TK Domain Mutations}

Activating mutations in the catalytic tyrosine kinase domain of EGFR, have been found to render tumor cells more sensitive to the TKIs (erlotinib and gefitinib) in lung cancer. These mutations led to gain-of-function and confer dependence of the tumor cell on the mutated kinase. The structural alterations associated with the mutational status favor an activated state of EGFR. In the absence of ligand binding the conformation is normally auto-inhibited [44]. EGFR activating mutations destabilize this conformation. An increase in kinase activity results. Tumor cells will show addiction to EGFR oncogene, with subsequent advantage in growth and survival. The mutated receptor presents higher sensitivity to erlotinib and gefitinib [45]. The most prevalent EGFR mutations of TK domain occur between exons 18 and 21. They consist in deletions in exon 19 (over 20 variant types) and a point mutation at codon 858 (L858R) in exon 21 [46]. As minor EGFR mutations, those at codon 719 (exon 18), 765 and 783 (exon 20) and in-frame insertion mutations in exon 20 have also been reported. These genomic alterations, differently to what was observed in NSCLC, are rare or absent in CRC and no significant association with clinical response of metastatic CRC to anti-EGFR mAbs has been found [47]. In addition this finding could support the observation that gefitinib is unlikely to be effective in patients with CRC. Almost all NSCLC patients, who are initially responders to TKIs, develop acquired resistance. This phenomenon was explained by the occurrence of a second point mutation [48]. The threonine-790 to methionine (T790M) point mutation was found in about a half of patients who experience progression during anti-EGFR TKIs therapy. It is rarely detected in tumors from untreated patients, since it is present at low levels. The selective pressure during treatment on those cells harbouring this mutation seems to lead to drug resistance. The T790M prevents the binding of reversible EGFR TKIs by steric hindrance or by enhanced affinity of the kinase domain for ATP $[49,50]$.

\subsubsection{Copy Number of EGFR Gene}

Many human malignant tumors have been found to have an elevated number of EGFR gene copies and various studies showed different results. In two trials it was established that probably only $10-15 \%$ of CRC show an increased EGFR copy number [51]. Even though the proportion of CRCs with EGFR gene amplification is relatively small, this genomic alteration seems to be an interesting predictor of response to anti-EGFR TKIs. Lenz et al. demonstrated a positive relationship between increased EGFR gene copy number (determined by quantitative PCR) and OS of patients, but not with PFS or response to cetuximab [52]. No correlations were found by Khambata-Ford S et al., between increased EGFR copy number and response to cetuximab [53]. Further studies are needed to establish the real value of this marker in clinical practice.

In NSCLC, the copy number of EGFR gene, seems to predict a real survival benefit with EGFR-TKI therapy [54]. In a systematic review and meta-analysis. Dahabreh et al. investgated EGFR gene copy number by fluorescent or chromogenic in situ hybridization in patients with advanced or recurrent NSCLC treated with the TKIs erlotinib or gefitinib [55]. They identified 255 studies, and among them, 20 for OS, 10 for PFS and 5 for TTP. The increase of EGFR gene copy number was associated with increased OS (HR $=0.77$; $95 \%$ CI $0.66-0.89 ; \mathrm{P}=0.001)$, PFS $(\mathrm{HR}=0.60 ; 95 \%$ CI $0.46-0.79$;
$\mathrm{P}<0.001)$ and TTP $(\mathrm{HR}=0.50 ; 95 \%$ CI $0.28-0.91 ; \mathrm{P}=0.02)$. The positive effects on overall survival were found only in Caucasians patients but not in the Asian population. This findings lead us to believe that there may be different mechanisms in the activation of the EGFR pathway in Asian populations, compared to Caucasians.

In the EXTREME study, the combination of chemotherapy (5FU/platinum) with cetuximab, in the first-line treatment of patients affected by recurrent and/or metastatic squamous cell carcinoma of the head and neck (SCCHN), determined an improvement in OS compared with CT alone. The purpose of the authors was to evaluate if the increase of EGFR copy number could be considered a marker of prediction. In those patients EGFR copy number was not associated with overall survival, progression-free survival or best overall response. EGFR copy number in tumor tissue doesn't seem a predictive biomarker for the efficacy of cetuximab plus 5FU/platinum as first-line therapy in patients with recurrent or metastatic SCCHN [56].

\subsubsection{Overexpression of New EGFR Ligands}

Amphiregulin (AREG) and epiregulin (EREG) belong to the epidermal growth factor (EGF) family, and work as endocrine mitogenic stimulators binding the EGF receptor (EGFR).The overexpression of these alternative EGFR ligands, has been evaluated by several studies and it has been associated with response to cetuximab treatment in CRC. Jacobs et al. established that the expression of EREG and AREG in primary tumors significantly predicts outcome in KRAS wild-type chemorefractory metastatic CRC treated with cetuximab and irinotecan. In particular, when these ligands are overexpressed, KRAS WT patients show a higher probability of response to anti-EGFR monoclonal antibodies. Instead low ligand expression in KRAS wild-type patients induce resistance to antiEGFR similar to that observed in patients with KRAS mutation. Thus these ligands together with the KRAS mutational status help to predict the outcomes of anti-EGFR therapy in CRC. Occasional ligand-independent responses were still observed, suggesting that additional markers are needed to improve response prediction [57].

\subsection{KRAS Mutational Status}

\subsubsection{KRAS in Colorectal Cancer}

KRAS is a proto-oncogene, whose relative protein is involved in the cellular response to many proliferation signals. The acquisition of mutations in KRAS leads to a state of permanent activity that allows the cell to obtain a proliferative advantage and to avoid apoptosis. Various human cancers, including pancreatic carcinoma, NSCLC and CRC, show KRAS activating mutations [58]. Kras results mutated in almost $40-45 \%$ of all colorectal adenocarcinomas and the most of its mutations are located on codon $12(70 \%)$ and codon $13(30 \%)$ and less in codon 61 [59]. These mutations result in an exchange of different amino acids at the catalytic sites which induce the glicine-to-valine substitution associated with a more aggressive tumor growth [60]. The predictive negative role of Kras' mutations, for the treatment with monoclonal antibodies (mAbs) vs Epidermal Growth Factor Receptor (EGFR) (Panitumumab and Cetuximab), is now a consolidated data and it has been demonstrated by several clinical studies. Kras wild type status is required for clinical application of mAbs in metastatic colorectal cancer (mCRC) but the prognostic role of the 12 possible Kras gene mutations on codons 12 and 13, has not yet been demonstrated. Further studies are needed to clarify the real impact of Kras mutations on the outcome of patients affected of CRC. The current international guidelines available, indicate as the unique possibility of using EGFR drugs, the assessment of wild type Kras status. Although Patients with 12 or 13 codon mutations in Kras are excluded from cetuximab treatment, Wendy De Roock et al., coducted a study [61] to assess how p.G13D-mutated CRCs responded to cetuximab therapy, in comparison with other KRAS mutations. 579 patients affected by chemorefractory CRC treated with cetuximab between 2001 and 2008 were studied. The primary endpoint was OS and 
secondary ORR, PFS. Patients affected by p.G13D-mutated CRC (n $=32$ ) treated with cetuximab showed a longer OS (median, 7.6 [95\% confidence interval [23], 5.7-20.5] months vs 5.7 [95\% CI, 4.9-6.8] months; adjusted hazard ratio [HR], 0.50; 95\% CI, 0.31$0.81 ; \mathrm{P}=.005$ ) and longer progression-free survival (median, 4.0 [95\% CI, 1.9-6.2] months vs 1.9 [95\% CI, 1.8-2.8] months; adjusted HR, $0.51 ; 95 \% \mathrm{CI}, 0.32-0.81 ; \mathrm{P}=.004)$. The use of cetuximab for the treatment of patients with p.G13D mutation of Kras, is associated with a better outcome then other KRAS-mutated tumors.

\subsubsection{KRAS in NSCLC}

KRAS mutations have been identified also in NSCLC but the utility of determining KRAS mutational status to predict clinical benefit to anti-EGFR therapies remains unclear ${ }^{62}$. Although an association between KRAS mutations and a lack of response to TKIs has been found, it is not clear how it can modify whether there is an association between KRAS mutation and EGFR TKI progression-free and overall survival. Neither the benefit from antiEGFR monoclonal antibodies seems to be correlated with KRAS mutational status in NSCLC [63].

\subsubsection{Detection Methods for KRAS Mutational Status.}

Several methods are now avalaible for the identification of KRAS mutations, and the most common are represented by direct sequencing analysis and real-time PCR. Direct sequencing is able to detect all Kras mutations in exons 2 and 3 of KRAS gene, but it has a poor sensitivity when compared with other methods. Real-time PCR uses primers binding the most common mutations in codon 12 and 13 and it has a sufficient level of sensitivity. The detection limit of these two tecniques is around $20 \%$ of the mutation rate. Pyrosequencing-based assay represents another effective method to identify Kras mutations. It is a DNA sequencing technique based on the detection of released pyrophosphate (PPi) during DNA synthesis [64] and it is more sensitive than traditional sequncing methods or real time PCR being able to detect mutation rate represented less than $20 \%$ of the analysed sample. An experience conduced by Santini's group has been built up to evaluate the real difference between pyrosequencing and the other routine techniques [65]. They selected 29 Formalin-fixed paraffin-embedded tumor samples from patients with primary CRC previously assessed by Real Time PCR and resulted wild type for codon 12/13 Kras mutations. These samples have been reanalyzed with both Real Time PCR and pyrosequencing assay at the same time: all of them resulted wild type after Real time but Kras mutation in codon $12 \mathrm{G}$ for $12 \mathrm{D}$ has been identified in three of the 29 samples. Mutations rate was between 18.2 and $20 \%$. Despite of the major sensitivity of pyrosequencing analisys and the lower limit rate for detection, these three mutated samples belonged to patients who had received a cetuximab-based chemotherapy, and showed partial response. Thus the identification of such allelic mutations' rate in Kras, lower than the $20 \%$ now avalaible with the current tecniques, seems not to lead to any more negative influence on patients' outcome. Thus, at the moment, pyrosequencing results have to be evaluated critically as a routine diagnostic test. Further evaluations on the real impact of such low frequencies of allelic mutations in Kras will be needed in a larger number of patients, to determine how they can induce changes in the clinical approach to patients with CRC and how they can influence the choose of an anti EGFR therapy.

\subsection{BRAF, PTEN and PIK3CA \\ 3.3.1. The Role of BRAF}

B-raf is a protoncogene which codificates for a Serine/threonine-protein kinase that plays an important role in the regulation of MAP kinase / ERKs signaling pathway and it is involved in a lot of cells functions like mitosis, differentiation and secretion. Activating mutations in B-raf have been recently described as an alternative oncogenic event in patients affected with mCRC without Kras mutations. The most common mutation is represented by a DNA mis- sense which lead to a valine to glutamic acid sobstitution (V600E). These mutations have been found in a relatively low number of CRC (approximately $10 \%$ ) and they are mutually exclusive with Kras mutations. Several studies have been conducted to evaluate the prognostic and predictive significance of B-raf mutations in WT KRAS CRC and a lot of them have confirmed the negative prognostic role of BRAF mutations. In K-RAS wild-type patients, BRAFmutated patients have shown a worse outcome in terms of PFS and OS. Loupakis et al. studied 87 patients affected by Kras codons 12 and 13 wild-type refractory $\mathrm{mCRC}$ treated with the assocaition of cetuximab and irinotecan, evaluated for the B-raf V600E and KRAS codon 61 and 146 mutations [66]. KRAS codons 61, 146 and BRAF V600E mutations were mutually exclusive. KRAS was mutated respectively in $7(8 \%)$ patients in codon 61 and in $1(1 \%)$ patient in codon 146 and none of these patients responded to the treatment. A shorter progression free survival (PFS) was associated with codon 61 and 146 mutations (median PFS: 3.8 vs 5.1 months in KRAS 61 and 146 wild type; HR: $0.46(0.11-0.88), P=0.028$;) but OS was not different in this two groups (median OS: 9.7 vs 14.7 months in KRAS 61 and 146 wild-type; HR: 0.69 (0.24-1.75), $P=0.390)$. B-raf V600E mutation was present in $13(15 \%)$ patients and none of them responded to therapy ( $0 \%$ vs $32 \%$ in BRAF wild-

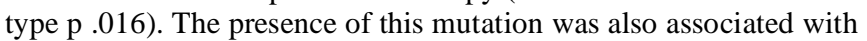
a shorter OS (4.1 months versus 13.9 months in BRAF wild-type HR $0.51(0.18-0.95) \mathrm{p}$.037). In another analysis by Di Nicolantonio et al.113 patients with mCRC treated with anti EGFR mAbs, were evaluated for RR, TTP (time to progression), OS and mutational status of K-RAS and BRAF. BRAF V600E mutation was detected in 11 of 79 patients (14\%) who had wild-type KRAS and no response to treatment has been observed in this group of patients. BRAF mutated patients had also a shorter PFS $(\mathrm{p}=0.011)$ and OS $(\mathrm{p}<.0001)$ than WT BRAF cases [67]. In the analysis of CRC cells in which the BRAF V600E mutated allele was introduced, the mutation impaired the effect of mAbs cetuximab or panitumumab in a similar way and the response to these drugs was restored with the introduction of sorafenib, a multikinase inhibitor.

\subsubsection{PTEN - PIK3CA - AKT - mTOR Pathway}

Phosphoinositide 3-kinase (PI3K) belongs to a family of enzymes which regulate many important cellular mechanisms, like cell's cycle progression and growth, apoptosis, migration, metabolism and vesicular trafficking. This enzymatic protein and its pathways are activated, in addition to KRAS and BRAF, also by the HER family receptors. PI3K function has been found to be deregulated in human cancers by activating mutations in the PIK3CA gene encoding p110 or by the genetic inactivation of phosphatase and tensin homologue (PTEN) gene, which normally functions as a tumor suppressor in the PI3K pathway that acts as a negative regulator of PI3K. PIK3CA/PTEN signaling deregulation has been found to condition the response to targeted therapy in diverse cancers by the activating mutations of PIK3, localized in exon 9 (E542K, E545K) and in exon 20 (H1047R) or by PTEN mutations or PTEN promoter methylation. These mutations occurs in almost $30 \%$ of colorectal cancers.

In a recent retrospective analysis the effects of PIK3CA gene mutations have been evaluated, together with KRAS, BRAF and NRAS mutations, to determine how they could influence the efficacy of the therapy with cetuximab plus chemotherapy in chemotherapy-refractory metastatic colorectal cancer [68]. In this study 773 primary tumour samples belonging patients with metastatic colorectal cancer and treated with cetuximab between 2001 and 2008, have been evaluated. The tumour samples were centrally analyzed with mass spectrometry genotyping, for KRAS, BRAF, NRAS, and PIK3CA mutations. The authors correlated these mutations with objective response, progression-free survival (PFS), and overall survival (OS), in 649 chemotherapy-refractory patients treated with cetuximab plus chemotherapy. The $14.5 \%(108 / 743)$ showed a PIK3CA mutation $(68.5 \%$ in exon 9 and $20.4 \%$ in exon 
20). No effect on the patients' outcome has been assessed in those with exon 9 PIK3CA mutations whereas exon 20 mutations were associated with a worse outcome compared with wild types: response rate $0 \%$ vs $36.8 \%$ (OR 0.00, 0.00-0.89; p=0.029) median PFS of 11.5 weeks versus 24 weeks (HR 2.52, 1.33-4.78; $\mathrm{p}=0.013$ ), and a median overall survival of 34 weeks versus 51 weeks (3.29, $1.60-6.74 ; \mathrm{p}=0.0057)$.

PTEN alterations are common in many tumour types including glioblastoma, prostate endometrial cancers and it occurs in almost the $18 \%$ in colorectal tumours with microsatellite instability (MSI+) [69]. PTEN loss in colorectal tumors is associated with lack of response to anti-EGFR monoclonal antibodies. Some authors found out that normal PTEN protein expression was associated with a higher response rate and longer time to progression in patients treated with cetuximab-based therapy, despite a $50 \%$ response rate was observed in patients who had lost PTEN protein expression. A retrospective analysis was performed by Loupakis et al. [70] on the status of PTEN in metastases from patients with irinotecanrefractatory colorectal cancer treated with irinotecan and cetuximab. $12(36 \%)$ of 33 patients with PTEN-positive metastases were responders compared with one (5\%) of 22 who had PTEN-negative metastases. Patients with PTEN-positive metastases and KRAS wild type had longer PFS compared with other patients.

\subsection{VEGF-related Predictive Factors \\ 3.4.1. Circulating Markers}

Recently attempted to determine predictive factors of response to Bevacizumab have been made above all in metastastic colo-rectal cancer (mCRC). In this view, CEA and CA19.9 are biomarkers routinely measured for monitoring treatment response in mCRC patients. Recently, out of 243 evaluated mCRC patients, 87 had biomarkers available as per inclusion criteria. Among all evaluated factors only type of treatment (chemotherapy-alone vs chemotherapy+bevacizumab) and baseline CA19.9 (> vs < normal) were independently associated with PFS, whilst neither baseline CEA nor biomarker reduction during therapy reached statistical significance. When patients with different baseline CA19.9 levels were analysed separately, only patients with abnormal CA19.9 benefited significantly from the administration of bevacizumab. This study demonstrated a significant predictive value of CA19.9, but not of CEA and biomarker reduction, for mCRC patients treated with bevacizumabbased chemotherapy. Moreover, only patients with abnormal baseline CA19.9 levels benefited significantly from bevacizumab [71]. Moreover, it was reported a sporadic correlation between the clinical response to FOLFOX/bevacizumab administration to a mCRC patient and the appearance of a skin rash even if no explanation of this effect was given [72].

\subsubsection{Circulating Tumour or Endothelial Progenitor Cells}

In mCRC patients enrolled in a randomised phase III study on capecitabine, oxaliplatin and bevacizumab with or without cetuximab (CAIRO 2 trial) the relevance of the changes in circulating tumor cells (CTCs) in predicting the response to treatment. CTC were determined at baseline and at different time points during treatment. Patients were stratified into low (less than three CTC per $7.5 \mathrm{ml}$ of blood) or high CTC (three or more CTC per $7.5 \mathrm{ml}$ of blood). A total of 467 patients were assessable for CTC analysis. Among them, 129 patients (29\%) with high baseline CTC had a significantly decreased progression-free survival [PFS; hazard ratio (HR) 1.5] and overall survival (OS; HR 2.2) compared with 322 patients with low baseline CTC. The sensitivity and specificity of high CTC at baseline for the prediction of progressive disease on CT imaging were $16.7 \%$ and $70.1 \%$, respectively, and of high CTC at $1-2$ weeks after the start of treatment $20.0 \%$ and $95.1 \%$, respectively [73].

Circulating endothelial cells (CECs) and haematopoietic progenitor cells (HPCs) might have a role in tumour angiogenesis and in tumour growth. Measurement of CECs and HPCs in the blood of patients could be a simple, non-invasive way to monitor or predict responses to treatment. In a recent study, CECs and HPCs were measured in blood from 25 non-small cell lung cancer (NSCLC) patients before and during treatment with sorafenib plus erlotinib (SO/ER). In order to assess the drug specificity of changes in CECs and HPCs, 18 patients treated with bevacizumab plus erlotinib (BV/ER) and 10 patients with erlotinib (ER) monotherapy were studied. Response was measured in all patient groups by RECIST. At day 7, SO/ER-treated patients showed a three-fold increase in CECs $(\mathrm{P}<0.0001)$ comparable to BV/ER-treated patients $(\mathrm{P}<0.01)$, and the CECs did not change with erlotinib treatment $(\mathrm{P}=0.8)$. At day 7, CD133(+)/HPCs decreased with SO/ER treatment $(\mathrm{P}<0.0001)$. HPC numbers did not change with either BV/ER or erlotinib. In SO/ER-treated patients pre-treatment CD133(+)/HPCs were significantly lower in responders $(\mathrm{P}=0.01)$ and pre-treatment CD133(+)/HPC numbers lower than the median correlated with a longer time-to-progression (TTP) $(\mathrm{P}=0.037)$. Pre-treatment CD133(+)/HPCs are a promising candidate biomarker to further explore for use in selecting NSCLC patients who might benefit from SO/ER treatmen, but not in BV/ER.

\subsubsection{Single Nucleotide Polymorphisms}

Another important issue in the prediction of response to bevacizumab is the study of genetic polymorphisms in VEGF genes. Till date, five functional SNPs in the 50 and 30 regions of the VEGF gene have been described [74-76]. The variant alleles of the $1154 \mathrm{G}>\mathrm{A}$ and $+936 \mathrm{C}>\mathrm{T}$ SNPs are associated with lower VEGF production [75, 7779], whereas the variant allele of the $-460 \mathrm{C}>\mathrm{T}$ SNP results in increased promoter activity [80]. There is less agreement on the functionality of the $-2578 \mathrm{C}>\mathrm{A}$ and $+405 \mathrm{G}>\mathrm{C}$ SNPs, as both increased and decreased VEGF production have been reported [76, 77, 79, 81]. It must be noted though that the abovementioned SNPs are inherited in clusters in so-called haplotype blocks (see glossary box) [76, 79, 80, 82-85]. It is likely that only one SNP is truly functional with regard to VEGF expression, whereas the others are merely proxies for this one. This truly causal SNP, however, has so far not been identified. There are several nonsynonymous SNPs in the coding region of the KDR gene (see http://www.ncbi.nlm.nih.gov/projects/SNP). Nonetheless, only functionality of a CA-repeat polymorphism in intron 2 of the KDR gene (+4422(AC)11-14) has been determined. The 11-repeat polymorphism results in higher promoter activity in vitro [86]. Even though the 11- and 12-repeat alleles were most common in the Japanese population, the allele frequencies in other populations are unknown.

In this view, a selection of 17 polymorphisms in genes encoding drug targets, pathway molecules and detoxification enzymes was analyzed in 279 previously untreated mCRC patients treated with capecitabine, oxaliplatin and bevacizumab (CAPOX-B). Multifactor dimensionality reduction analysis was used to identify a genetic interaction profile for PFS. Median PFS was 10.9 [95\% confidence interval (CI) 9.4-12.4] months. A genetic interaction profile consisting of the TYMS enhancer region and VEGF $+405 \mathrm{G}>\mathrm{C}$ polymorphisms was significantly associated with PFS. Median PFS was 13.3 (95\% CI 11.4-15.3) and 9.7 (95\% CI 7.611.8) months for the beneficial and unfavorable genetic profiles, respectively, corresponding to a hazards ratio for PFS of 1.58 (95\% CI 1.14-2.19). None of the studied polymorphisms were individually associated with PFS [87]. In the BOND-2 trial, mCRC patients progressing after irinotecan-based chemotherapy were randomized to receive irinotecan plus bevacizumab plus cetuximab (CBI) or bevacizumab and cetuximab (CB). In this trial, germline polymorphisms involved in angiogenesis (vascular endothelial growth factor [VEGF], interleukin-8 [IL-8], transforming growth factor [TGF]$\beta$ ), the epidermal growth factor receptor (EGFR) pathway (EGFR, cyclooxygenase-2, Ecadherin), DNA repair (ERCC1, ERCC2, $\mathrm{XRCC} 1$, xeroderma pigmentosum group D [XPD]), and drug me- 
tabolism pathway (GSTP1, UGT1A1) were investigated. No correlation with VEGF gene polymorphisms was however found [88]. Recently two studies evaluated the relationship of VEGF plasma levels or somatic VEGF and VEGFR-2 SNPs with treatment efficacy or toxicity in breast cancer. One of them compared the effect of paclitaxel with paclitaxel and bevacizumab combination in metastatic breast cancer by enrolling 183 patients in each arm [89]. The VEGF-2578AA had longer median overall survival (HR 0.58) compared with the $-2578 \mathrm{CA}+\mathrm{CC}$ genotype in the combination arm. Similarly -1154A allele had longer overall survival (HR 0.62) in the combination arm, which increased additively with increase in number of A alleles. VEGF -634CC and -1498TT had significantly less likelihood of developing grade 3 or 4 hypertension in the combination arm compared with $-634 \mathrm{GC}+\mathrm{GG}$ and $-1498 \mathrm{CT}+\mathrm{CC}$, respectively. The VEGF 936C > T, VEGFR-2 889G > A, and VEGFR-2 $1416 \mathrm{~A}>\mathrm{T}$ had no significant relationship with either the efficacy or toxicity. Another study enrolled 56 breast cancer patients to examine the role of plasma VEGF levels as a predictor of treatment outcome with bevacizumab and vinorelbine therapy [90]. Lower levels of baseline VEGF predicted longer progression free survival.

\section{PREDICTIVE FACTORS OF TOXICITY}

During cancer therapy with EGFR inhibitors, rash is the most common side effect. The face, trunk, and upper extremities are the most common sites of its onset, which occurs within 1 week of starting treatment. This phenomenon resulted severe in $5-10 \%$ of patients [91]. Patients' quality of life is then compromised by cutaneous pain and hypersensitivity, worries about appearance, and frustration from having to contend with this side effect [92]. Up till now we lack preventive and palliative options. Predictive factors of skin toxicity would enable healthcare providers to counsel patients about the prospect of a severe rash, thereby allowing patients to prepare themselves emotionally for this disfiguring, uncomfortable side effect $[93,94]$. Few studies have focused on factors associated with rash development. Pharmacokinetic and pharmacogenomic models are starting to be explored.

EGFR inhibitors may have less cutaneous toxicity in older patients, because they express fewer cutaneous targets. Infact, in advanced age, cultured fibroblasts express fewer EGFR protein [95].

Besides, because androgens and estrogens also appear to interact with EGFR, these hormonal interactions could support the different rates of rash developed based on gender [96].

Lai et al. preliminarily reported on 42 patients and observed that lighter skin pigmentation was associated with higher rates of rash from erlotinib [97].

Wacker et al. observed a lose association between performance score and rash development in 444 cancer patients treated with antiEGFR TKIs in two large phase III studies [98].

The toxicities experienced by patients taking erlotinib are multifactorial and determined by distinct parameters in different tissues. Erlotinib pharmacokinetics has an interindividual variability, which correlates with skin toxicity. It also correlated with erlotinib exposure levels, together with the observed association between skin toxicity and survival. Alternative determinants of interindividual susceptibility to rash and diarrhea are likely, but remain to be identified. Just a full understanding variable toxicity to anti-EGFR agents could allow a better management of the currently available agents, with definition of the optimal doses and in patients most likely to benefit [99].

In an adjuvant chemotherapy trial for colon cancer, 933 cetuximab-treated patients were evaluated for clinical risk factors of severe rash. Severe rash among cetuximab-treated patients was more commonly observed in men and younger patients. More men compared to women developed a grade 3 rash: 34 (7\%) versus $16(3 \%)$ (multivariate odds ratio $=2.10 ; 95 \%$ confidence interval: $1.14-3.88$; $\mathrm{p}=0.017)$. Similarly, a greater number of younger patients $(<70$ years of age) developed a grade 3 rash: $48(6 \%)$ versus $2(1 \%)$ (multivariate odds ratio $=0.21 ; 95 \%$ confidence interval: $0.05-0.88$; $\mathrm{p}=0.032$ ) [100].

\section{CONCLUSIONS}

EGFR-related pathway has long been considered one of the most relevant molecular machinery for cancer development and progression. VEGF has been identified as the main responsible of tumor growth, since its overproduction by tumor cells induces the formation of new vessels. The researchers argued that the blockade of these molecular mechanisms could be a valid chance to inhibit tumor progression and subsequently to manage cancer patients. Various clinical trials showed that some of these molecules need the combination with chemotherapy to yield a significant benefit, as was found for bevacizumab and cetuximab. Other drugs, such as the tyrosine kinase inhibitors and the anti-EGFR monoclonal antibody panitumumab, were recognized to function as monotherapy.

The definition of clinical characteristics and biomarkers to select those patients, who really benefit as consequence of these agents, was prompted by the great concern to spend eager financial resources to obtain benefit just in a few subgroups of patients. For the anti-EGFR TKIs the search of EGFR gene activating mutations seems a valid opportunity to detect those patients who have high probability of response and survival benefit. However, up till now it is not fully clear whether a small part of the patients without those mutations could receive benefit from treatment with TKIs.

More clear is the role of KRAS gene activating mutations for the decision of treatment with anti-EGFR monoclonal antibodies in colorectal cancer patients. The presence of those mutations is able to predict resistance to cetuximab and panitumumab, regardless the combination with chemotherapy. In fact no responses to these drugs were observed, when delivered to the patients with activating mutations. Other biomarkers, which belong to the EGFR pathway, are under evaluation to restrict the treatment to KRAS wild-type patients who have very high probability of response.

To date we cannot select patients for treatment with anti-VEGF molecules, because predictive factors for their efficacy were not yet identified. Various circulating markers and cancer cells or endothelial cells, together with single nucleotide polymorphism are under evaluation. Interesting results suggested that the researchers should focus on these predictive factors. Anyway these findings could not yet be translated into clinical practice applications.

Just few we know about predictive factors of toxicity. Skin rash favoured a great limitation of treatment with anti-EGFR agents. However the prevention or correction of these phenomenon is more useful than its prediction. So all our efforts should allow the accurate management of toxicity to continue the treatment in those patients who show clear benefit.

\section{REFERENCES}

[1] Bazley, L. A.; Gullick, W. J., The epidermal growth factor receptor family. Endocr. Relat. Cancer, 2005, 12 Suppl 1, S17-27.

[2] Kumar, A.; Petri, E. T.; Halmos, B.; Boggon, T. J., Structure and clinical relevance of the epidermal growth factor receptor in human cancer. J.Clin. Oncol., 2008, 26(10), 1742-1751.

[3] Campbell, P. M.; Der, C. J., Oncogenic Ras and its role in tumor cell invasion and metastasis. Semin. Cancer Biol., 2004, 14(2), $105-114$.

[4] Avruch, J.; Khokhlatchev, A.; Kyriakis, J. M.; Luo, Z.; Tzivion, G.; Vavvas, D.; Zhang, X. F., Ras activation of the Raf kinase: tyrosine kinase recruitment of the MAP kinase cascade. Recent Prog. Horm. Res., 2001, 56 127-155.

[5] Montagut, C.; Settleman, J., Targeting the RAF-MEK-ERK pathway in cancer therapy. Cancer Lett., 2009, 283(2), 125-134.

[6] Roberts, P. J.; Der, C. J., Targeting the Raf-MEK-ERK mitogenactivated protein kinase cascade for the treatment of cancer. Oncogene, 2007, 26(22), 3291-310. 
[7] Neufeld, G.; Cohen, T.; Gengrinovitch, S.; Poltorak, Z., Vascular endothelial growth factor (VEGF) and its receptors. Faseb. J., 1999, 13(1), 9-22.

[8] Poltorak, Z.; Cohen, T.; Sivan, R.; Kandelis, Y.; Spira, G.; Vlodavsky, I.; Keshet, E.; Neufeld, G., VEGF145, a secreted vascular endothelial growth factor isoform that binds to extracellular matrix. J. Biol. Chem., 1997, 272(11), 7151-7158.

[9] Robinson, C. J.; Stringer, S. E., The splice variants of vascular endothelial growth factor (VEGF) and their receptors. J. Cell Sci., 2001, 114(Pt 5), 853-865.

[10] Ferrara, N.; Gerber, H. P.; LeCouter, J., The biology of VEGF and its receptors. Nat. Med., 2003, 9(6), 669-676.

[11] Fischer, C.; Mazzone, M.; Jonckx, B.; Carmeliet, P., FLT1 and its ligands VEGFB and PIGF: drug targets for anti-angiogenic therapy? Nat. Rev. Cancer, 2008, 8(12), 942-956.

[12] Miao, H. Q.; Klagsbrun, M., Neuropilin is a mediator of angiogenesis. Cancer Metastasis Rev., 2000, 19(1-2), 29-37.

[13] Takashima, S.; Kitakaze, M.; Asakura, M.; Asanuma, H.; Sanada, S.; Tashiro, F.; Niwa, H.; Miyazaki Ji, J.; Hirota, S.; Kitamura, Y.; Kitsukawa, T.; Fujisawa, H.; Klagsbrun, M.; Hori, M., Targeting of both mouse neuropilin-1 and neuropilin-2 genes severely impairs developmental yolk sac and embryonic angiogenesis. Proc. Natl. Acad. Sci. USA, 2002, 99(6), 3657-3662.

[14] Hiratsuka, S.; Minowa, O.; Kuno, J.; Noda, T.; Shibuya, M., Flt-1 lacking the tyrosine kinase domain is sufficient for normal development and angiogenesis in mice. Proc. Natl. Acad. Sci. USA, 1998, 95(16), 9349-9354.

[15] Autiero, M.; Waltenberger, J.; Communi, D.; Kranz, A.; Moons, L.; Lambrechts, D.; Kroll, J.; Plaisance, S.; De Mol, M.; Bono, F.; Kliche, S.; Fellbrich, G.; Ballmer-Hofer, K.; Maglione, D.; MayrBeyrle, U.; Dewerchin, M.; Dombrowski, S.; Stanimirovic, D.; Van Hummelen, P.; Dehio, C.; Hicklin, D. J.; Persico, G.; Herbert, J. M.; Communi, D.; Shibuya, M.; Collen, D.; Conway, E. M.; Carmeliet, P., Role of PIGF in the intra- and intermolecular cross talk between the VEGF receptors Flt1 and Flk1. Nat. Med., 2003, 9(7), 936-943.

[16] Cook, K. M.; Figg, W. D., Angiogenesis inhibitors: current strategies and future prospects. CA Cancer J. Clin., 2010, 60(4), 222243.

[17] Cunningham, D.; Humblet, Y.; Siena, S.; Khayat, D.; Bleiberg, H.; Santoro, A.; Bets, D.; Mueser, M.; Harstrick, A.; Verslype, C.; Chau, I.; Van Cutsem, E., Cetuximab monotherapy and cetuximab plus irinotecan in irinotecan-refractory metastatic colorectal cancer. N. Engl. J. Med., 2004, 351(4), 337-345.

[18] Sobrero, A. F.; Maurel, J.; Fehrenbacher, L.; Scheithauer, W.; Abubakr, Y. A.; Lutz, M. P.; Vega-Villegas, M. E.; Eng, C.; Steinhauer, E. U.; Prausova, J.; Lenz, H. J.; Borg, C.; Middleton, G.; Kroning, H.; Luppi, G.; Kisker, O.; Zubel, A.; Langer, C.; Kopit, J.; Burris, H. A., 3rd, EPIC: phase III trial of cetuximab plus irinotecan after fluoropyrimidine and oxaliplatin failure in patients with metastatic colorectal cancer. J. Clin. Oncol., 2008, 26(14), 2311-2319.

[19] Jonker, D. J.; O'Callaghan, C. J.; Karapetis, C. S.; Zalcberg, J. R.; Tu, D.; Au, H. J.; Berry, S. R.; Krahn, M.; Price, T.; Simes, R. J.; Tebbutt, N. C.; van Hazel, G.; Wierzbicki, R.; Langer, C.; Moore, M. J., Cetuximab for the treatment of colorectal cancer. N. Engl. J. Med., 2007, 357(20), 2040-2048.

[20] Van Cutsem, E.; Kohne, C. H.; Hitre, E.; Zaluski, J.; Chang Chien, C. R.; Makhson, A.; D'Haens, G.; Pinter, T.; Lim, R.; Bodoky, G.; Roh, J. K.; Folprecht, G.; Ruff, P.; Stroh, C.; Tejpar, S.; Schlichting, M.; Nippgen, J.; Rougier, P., Cetuximab and chemotherapy as initial treatment for metastatic colorectal cancer. $N$. Engl. J. Med., 2009, 360(14), 1408-1417.

[21] Bokemeyer, C.; Bondarenko, I.; Makhson, A.; Hartmann, J. T.; Aparicio, J.; de Braud, F.; Donea, S.; Ludwig, H.; Schuch, G.; Stroh, C.; Loos, A. H.; Zubel, A.; Koralewski, P., Fluorouracil, leucovorin, and oxaliplatin with and without cetuximab in the firstline treatment of metastatic colorectal cancer. J. Clin. Oncol., 2009, 27(5), 663-671.

[22] Van Cutsem, E.; Peeters, M.; Siena, S.; Humblet, Y.; Hendlisz, A.; Neyns, B.; Canon, J. L.; Van Laethem, J. L.; Maurel, J.; Richardson, G.; Wolf, M.; Amado, R. G., Open-label phase III trial of panitumumab plus best supportive care compared with best supportive care alone in patients with chemotherapy-refractory metastatic colorectal cancer. J. Clin. Oncol., 2007, 25(13), 1658-64.
Amado, R. G.; Wolf, M.; Peeters, M.; Van Cutsem, E.; Siena, S.; Freeman, D. J.; Juan, T.; Sikorski, R.; Suggs, S.; Radinsky, R.; Patterson, S. D.; Chang, D. D., Wild-type KRAS is required for panitumumab efficacy in patients with metastatic colorectal cancer. $J$. Clin. Oncol., 2008, 26(10), 1626-1634.

[24] Van Cutsem, E.; Siena, S.; Humblet, Y.; Canon, J. L.; Maurel, J.; Bajetta, E.; Neyns, B.; Kotasek, D.; Santoro, A.; Scheithauer, W.; Spadafora, S.; Amado, R. G.; Hogan, N.; Peeters, M., An openlabel, single-arm study assessing safety and efficacy of panitumumab in patients with metastatic colorectal cancer refractory to standard chemotherapy. Ann. Oncol., 2008, 19(1), 92-98.

[25] Rosell, R.; Moran, T.; Queralt, C.; Porta, R.; Cardenal, F.; Camps, C.; Majem, M.; Lopez-Vivanco, G.; Isla, D.; Provencio, M.; Insa, A.; Massuti, B.; Gonzalez-Larriba, J. L.; Paz-Ares, L.; Bover, I.; Garcia-Campelo, R.; Moreno, M. A.; Catot, S.; Rolfo, C.; Reguart, N.; Palmero, R.; Sanchez, J. M.; Bastus, R.; Mayo, C.; BertranAlamillo, J.; Molina, M. A.; Sanchez, J. J.; Taron, M., Screening for epidermal growth factor receptor mutations in lung cancer. $N$. Engl. J. Med., 2009, 361(10), 958-967.

[26] Yoshida, K.; Yatabe, Y.; Park, J. Y.; Shimizu, J.; Horio, Y.; Matsuo, K.; Kosaka, T.; Mitsudomi, T.; Hida, T., Prospective validation for prediction of gefitinib sensitivity by epidermal growth factor receptor gene mutation in patients with non-small cell lung cancer. J. Thorac. Oncol., 2007, 2(1), 22-28.

[27] Mok, T. S.; Wu, Y. L.; Thongprasert, S.; Yang, C. H.; Chu, D. T.; Saijo, N.; Sunpaweravong, P.; Han, B.; Margono, B.; Ichinose, Y.; Nishiwaki, Y.; Ohe, Y.; Yang, J. J.; Chewaskulyong, B.; Jiang, H.; Duffield, E. L.; Watkins, C. L.; Armour, A. A.; Fukuoka, M., Gefitinib or carboplatin-paclitaxel in pulmonary adenocarcinoma. $N$ Engl. J. Med., 2009, 361(10), 947-957.

[28] Thongprasert, S. In Quality of life in a randomised Phase III firstline study of gefitinib vs. carboplatin/paclitaxel in clinically selected Asian patients with advanced non small cell lung cancer (IPASS), IASLC-ESMO meeting, 2010; 2010.

[29] Yang, C. In Final overall survival (OS) results from a phase III: randomised, open-label, first-line study of gefitinib $(G)$ vs carboplatin/paclitaxel $(C / P)$ in clinically selected patients with advanced non-small cell lung cancer (NSCLC) in Asia (IPASS), European Society of Medical Oncology (ESMO) Congress, 2010; 2010.

[30] Shepherd, F. A.; Rodrigues Pereira, J.; Ciuleanu, T.; Tan, E. H.; Hirsh, V.; Thongprasert, S.; Campos, D.; Maoleekoonpiroj, S.; Smylie, M.; Martins, R.; van Kooten, M.; Dediu, M.; Findlay, B.; Tu, D.; Johnston, D.; Bezjak, A.; Clark, G.; Santabarbara, P.; Seymour, L., Erlotinib in previously treated non-small-cell lung cancer. N. Engl. J. Med., 2005, 353(2), 123-132.

[31] Cappuzzo, F.; Ciuleanu, T.; Stelmakh, L.; Cicenas, S.; Szczesna, A.; Juhasz, E.; Esteban, E.; Molinier, O.; Brugger, W.; Melezinek, I.; Klingelschmitt, G.; Klughammer, B.; Giaccone, G., Erlotinib as maintenance treatment in advanced non-small-cell lung cancer: a multicentre, randomised, placebo-controlled phase 3 study. Lancet Oncol., 2010, 11(6), 521-529.

[32] Kim, K. J.; Li, B.; Winer, J.; Armanini, M.; Gillett, N.; Phillips, H. S.; Ferrara, N., Inhibition of vascular endothelial growth factorinduced angiogenesis suppresses tumour growth in vivo. Nature, 1993, 362(6423), 841-844.

[33] Hurwitz, H.; Fehrenbacher, L.; Novotny, W.; Cartwright, T. Hainsworth, J.; Heim, W.; Berlin, J.; Baron, A.; Griffing, S.; Holmgren, E.; Ferrara, N.; Fyfe, G.; Rogers, B.; Ross, R.; Kabbinavar, F., Bevacizumab plus irinotecan, fluorouracil, and leucovorin for metastatic colorectal cancer. $N$. Engl. J. Med., 2004, 350 (23), 2335-2342.

[34] Miller, K. D.; Chap, L. I.; Holmes, F. A.; Cobleigh, M. A.; Marcom, P. K.; Fehrenbacher, L.; Dickler, M.; Overmoyer, B. A.; Reimann, J. D.; Sing, A. P.; Langmuir, V.; Rugo, H. S., Randomized phase III trial of capecitabine compared with bevacizumab plus capecitabine in patients with previously treated metastatic breast cancer. J. Clin. Oncol., 2005, 23(4), 792-799.

[35] Miller, K.; Wang, M.; Gralow, J.; Dickler, M.; Cobleigh, M.; Perez, E. A.; Shenkier, T.; Cella, D.; Davidson, N. E., Paclitaxel plus bevacizumab versus paclitaxel alone for metastatic breast cancer. N. Engl. J. Med., 2007, 357(26), 2666-2676.

[36] Johnson, D. H.; Fehrenbacher, L.; Novotny, W. F.; Herbst, R. S Nemunaitis, J. J.; Jablons, D. M.; Langer, C. J.; DeVore, R. F., 3rd; Gaudreault, J.; Damico, L. A.; Holmgren, E.; Kabbinavar, F., Randomized phase II trial comparing bevacizumab plus carboplatin and 
paclitaxel with carboplatin and paclitaxel alone in previously untreated locally advanced or metastatic non-small-cell lung cancer. J. Clin. Oncol., 2004, 22(11), 2184-2191.

[37] Sandler, A.; Gray, R.; Perry, M. C.; Brahmer, J.; Schiller, J. H.; Dowlati, A.; Lilenbaum, R.; Johnson, D. H., Paclitaxel-carboplatin alone or with bevacizumab for non-small-cell lung cancer. $N$. Engl. J. Med., 2006, 355(24), 2542-2550.

[38] Holash, J.; Davis, S.; Papadopoulos, N.; Croll, S. D.; Ho, L.; Russell, M.; Boland, P.; Leidich, R.; Hylton, D.; Burova, E.; Ioffe, E.; Huang, T.; Radziejewski, C.; Bailey, K.; Fandl, J. P.; Daly, T.; Wiegand, S. J.; Yancopoulos, G. D.; Rudge, J. S., VEGF-Trap: a VEGF blocker with potent antitumor effects. Proc. Natl. Acad. Sci. U S A, 2002, 99(17), 11393-11398.

[39] Tew, W. P.; Colombo, N.; Ray-Coquard, I.; Oza, A.; del Campo, J.; Scambia, G.; Spriggs, D., VEGF-Trap for patients (pts) with recurrent platinum-resistant epithelial ovarian cancer (EOC): Preliminary results of a randomized, multicenter phase II study. J. Clin. Oncol., 2007, 25, (18S (June 20 Supplement)).

[40] Massarelli, E.; Miller, V. A.; Leighl, N. B.; Rosen, P. J.; Albain, K. S.; Hart, L. L.; Melnyk, O.; Sternas, L.; Ackerman, J.; Herbst, R. S., Phase II study of the efficacy and safety of intravenous (IV) AVE0005 (VEGF Trap) given every 2 weeks in patients (Pts) with platinum- and erlotinib- resistant adenocarcinoma of the lung (NSCLA). J. Clin. Oncol., 2007, 25, (18S (June 20 Supplement)).

[41] Hobday, T. J.; Rowland, K.; Dueck, A.; Northfelt, D.; Lingle, W.; Morton, R.; Fitch, T.; Nikcevich, D.; Perez, E. A. In N0537: A North Central Cancer Treatment Group (NCCTG) phase II trial of $V E G F$ Trap in patients with metastatic breast cancer $(M B C)$ previously treated with an anthracycline and/or a taxane, Breast Cancer Symposium 2008.

[42] Spano, J. P.; Milano, G.; Vignot, S.; Khayat, D., Potential predictive markers of response to EGFR-targeted therapies in colorectal cancer. Crit. Rev. Oncol. Hematol., 2008, 66(1), 21-30.

[43] Chung, K. Y.; Shia, J.; Kemeny, N. E.; Shah, M.; Schwartz, G. K.; Tse, A.; Hamilton, A.; Pan, D.; Schrag, D.; Schwartz, L.; Klimstra, D. S.; Fridman, D.; Kelsen, D. P.; Saltz, L. B., Cetuximab shows activity in colorectal cancer patients with tumors that do not express the epidermal growth factor receptor by immunohistochemistry. J. Clin. Oncol., 2005, 23(9), 1803-1810.

[44] Zhang, X.; Gureasko, J.; Shen, K.; Cole, P. A.; Kuriyan, J., An allosteric mechanism for activation of the kinase domain of epidermal growth factor receptor. Cell, 2006, 125(6), 1137-1149.

[45] Carey, K. D.; Garton, A. J.; Romero, M. S.; Kahler, J.; Thomson, S.; Ross, S.; Park, F.; Haley, J. D.; Gibson, N.; Sliwkowski, M. X., Kinetic analysis of epidermal growth factor receptor somatic mutant proteins shows increased sensitivity to the epidermal growth factor receptor tyrosine kinase inhibitor, erlotinib. Cancer Res., 2006, 66(16), 8163-8171.

[46] Mitsudomi, T.; Yatabe, Y., Mutations of the epidermal growth factor receptor gene and related genes as determinants of epidermal growth factor receptor tyrosine kinase inhibitors sensitivity in lung cancer. Cancer Sci., 2007, 98(12), 1817-1824.

[47] Moroni, M.; Sartore-Bianchi, A.; Benvenuti, S.; Artale, S.; Bardelli, A.; Siena, S., Somatic mutation of EGFR catalytic domain and treatment with gefitinib in colorectal cancer. Ann. Oncol., 2005, 16(11), 1848-1849.

[48] Kobayashi, S.; Boggon, T. J.; Dayaram, T.; Janne, P. A.; Kocher, O.; Meyerson, M.; Johnson, B. E.; Eck, M. J.; Tenen, D. G.; Halmos, B., EGFR mutation and resistance of non-small-cell lung cancer to gefitinib. N. Engl. J. Med., 2005, 352(8), 786-792.

[49] Balak, M. N.; Gong, Y.; Riely, G. J.; Somwar, R.; Li, A. R.; Zakowski, M. F.; Chiang, A.; Yang, G.; Ouerfelli, O.; Kris, M. G.; Ladanyi, M.; Miller, V. A.; Pao, W., Novel D761Y and common secondary T790M mutations in epidermal growth factor receptormutant lung adenocarcinomas with acquired resistance to kinase inhibitors. Clin. Cancer Res., 2006, 12(21), 6494-6501.

[50] Pao, W.; Miller, V. A.; Politi, K. A.; Riely, G. J.; Somwar, R.; Zakowski, M. F.; Kris, M. G.; Varmus, H., Acquired resistance of lung adenocarcinomas to gefitinib or erlotinib is associated with a second mutation in the EGFR kinase domain. PLoS Med., 2005, 2 (3), e73.

[51] Shia, J.; Klimstra, D. S.; Li, A. R.; Qin, J.; Saltz, L.; TeruyaFeldstein, J.; Akram, M.; Chung, K. Y.; Yao, D.; Paty, P. B.; Gerald, W.; Chen, B., Epidermal growth factor receptor expression and gene amplification in colorectal carcinoma: an immunohistochemi- cal and chromogenic in situ hybridization study. Mod. Pathol., 2005, 18(10), 1350-1356.

[52] Lenz, H. J.; Van Cutsem, E.; Khambata-Ford, S.; Mayer, R. J.; Gold, P.; Stella, P.; Mirtsching, B.; Cohn, A. L.; Pippas, A. W.; Azarnia, N.; Tsuchihashi, Z.; Mauro, D. J.; Rowinsky, E. K., Multicenter phase II and translational study of cetuximab in metastatic colorectal carcinoma refractory to irinotecan, oxaliplatin, and fluoropyrimidines. J. Clin. Oncol., 2006, 24(30), 4914-4921.

[53] Khambata-Ford, S.; Garrett, C. R.; Meropol, N. J.; Basik, M.; Harbison, C. T.; Wu, S.; Wong, T. W.; Huang, X.; Takimoto, C. H.; Godwin, A. K.; Tan, B. R.; Krishnamurthi, S. S.; Burris, H. A., 3rd; Poplin, E. A.; Hidalgo, M.; Baselga, J.; Clark, E. A.; Mauro, D. J., Expression of epiregulin and amphiregulin and K-ras mutation status predict disease control in metastatic colorectal cancer patients treated with cetuximab. J. Clin. Oncol., 2007, 25(22), 32303237.

[54] Carlson, J. J.; Garrison, L. P.; Ramsey, S. D.; Veenstra, D. L., Epidermal growth factor receptor genomic variation in NSCLC patients receiving tyrosine kinase inhibitor therapy: a systematic review and meta-analysis. J. Cancer Res. Clin. Oncol., 2009, 135 (11), 1483-1493.

[55] Dahabreh, I. J.; Linardou, H.; Kosmidis, P.; Bafaloukos, D.; Murray, S., EGFR gene copy number as a predictive biomarker for patients receiving tyrosine kinase inhibitor treatment: a systematic review and meta-analysis in non-small-cell lung cancer. Ann. Oncol., 2011, 22(3), 545-552.

[56] Licitra, L.; Mesia, R.; Rivera, F.; Remenar, E.; Hitt, R.; Erfan, J.; Rottey, S.; Kawecki, A.; Zabolotnyy, D.; Benasso, M.; Storkel, S.; Senger, S.; Stroh, C.; Vermorken, J. B., Evaluation of EGFR gene copy number as a predictive biomarker for the efficacy of cetuximab in combination with chemotherapy in the first-line treatment of recurrent and/or metastatic squamous cell carcinoma of the head and neck: EXTREME study. Ann. Oncol., 2010.

[57] Jacobs, B.; De Roock, W.; Piessevaux, H.; Van Oirbeek, R.; Biesmans, B.; De Schutter, J.; Fieuws, S.; Vandesompele, J.; Peeters, M.; Van Laethem, J. L.; Humblet, Y.; Penault-Llorca, F.; De Hertogh, G.; Laurent-Puig, P.; Van Cutsem, E.; Tejpar, S., Amphiregulin and epiregulin mRNA expression in primary tumors predicts outcome in metastatic colorectal cancer treated with cetuximab. J. Clin. Oncol., 2009, 27(30), 5068-5074.

[58] Downward, J., Targeting RAS signalling pathways in cancer therapy. Nat. Rev. Cancer, 2003, 3(1), 11-22.

[59] Andreyev, H. J.; Norman, A. R.; Cunningham, D.; Oates, J.; Dix, B. R.; Iacopetta, B. J.; Young, J.; Walsh, T.; Ward, R.; Hawkins, N.; Beranek, M.; Jandik, P.; Benamouzig, R.; Jullian, E.; LaurentPuig, P.; Olschwang, S.; Muller, O.; Hoffmann, I.; Rabes, H. M.; Zietz, C.; Troungos, C.; Valavanis, C.; Yuen, S. T.; Ho, J. W.; Croke, C. T.; O'Donoghue, D. P.; Giaretti, W.; Rapallo, A.; Russo, A.; Bazan, V.; Tanaka, M.; Omura, K.; Azuma, T.; Ohkusa, T.; Fujimori, T.; Ono, Y.; Pauly, M.; Faber, C.; Glaesener, R.; de Goeij, A. F.; Arends, J. W.; Andersen, S. N.; Lovig, T.; Breivik, J.; Gaudernack, G.; Clausen, O. P.; De Angelis, P. D.; Meling, G. I.; Rognum, T. O.; Smith, R.; Goh, H. S.; Font, A.; Rosell, R.; Sun, X. F.; Zhang, H.; Benhattar, J.; Losi, L.; Lee, J. Q.; Wang, S. T.; Clarke, P. A.; Bell, S.; Quirke, P.; Bubb, V. J.; Piris, J.; Cruickshank, N. R.; Morton, D.; Fox, J. C.; Al-Mulla, F.; Lees, N.; Hall, C. N.; Snary, D.; Wilkinson, K.; Dillon, D.; Costa, J.; Pricolo, V. E.; Finkelstein, S. D.; Thebo, J. S.; Senagore, A. J.; Halter, S. A.; Wadler, S.; Malik, S.; Krtolica, K.; Urosevic, N., Kirsten ras mutations in patients with colorectal cancer: the 'RASCAL II' study. $B r$. J. Cancer, 2001, 85(5), 692-696.

[60] Boughdady, I. S.; Kinsella, A. R.; Haboubi, N. Y.; Schofield, P. F., $\mathrm{K}$-ras gene mutation in colorectal adenomas and carcinomas from familial adenomatous polyposis patients. Surg. Oncol., 1992, 1(4), 269-274.

[61] De Roock, W.; Jonker, D. J.; Di Nicolantonio, F.; Sartore-Bianchi, A.; Tu, D.; Siena, S.; Lamba, S.; Arena, S.; Frattini, M.; Piessevaux, H.; Van Cutsem, E.; O'Callaghan, C. J.; Khambata-Ford, S.; Zalcberg, J. R.; Simes, J.; Karapetis, C. S.; Bardelli, A.; Tejpar, S., Association of KRAS p.G13D mutation with outcome in patients with chemotherapy-refractory metastatic colorectal cancer treated with cetuximab. JAMA, 2010, 304(16), 1812-1820.

[62] Roberts, P. J.; Stinchcombe, T. E.; Der, C. J.; Socinski, M. A., Personalized medicine in non-small-cell lung cancer: is KRAS a useful marker in selecting patients for epidermal growth factor receptor-targeted therapy? J. Clin. Oncol., 2010, 28(31), 4769-4777. 
[63] O'Byrne, K. J.; Bondarenko, I.; Barrios, C.; Eschbach, C.; Martens, U.; Hotko, Y.; Kortsik, C.; Celik, I.; Stroh, C.; Pirker, R. In Molecular and clinical predictors of outcome for cetuximab in nonsmall cell lung cancer (NSCLC): Data from the FLEX study, ASCO Annual Meeting 2009.

[64] Ronaghi, M., Pyrosequencing sheds light on DNA sequencing. Genome Res., 2001, 11(1), 3-11.

[65] Santini, D.; Galluzzo, S.; Gaeta, L.; Zoccoli, A.; Riva, E.; Ruzzo, A.; Vincenzi, B.; Graziano, F.; Loupakis, F.; Falcone, A.; Muda, A. O.; Tonini, G., Should Oncologists Be Aware in Their Clinical Practice of KRAS Molecular Analysis? J. Clin. Oncol., 2011, 29 (8), e206-207.

[66] Loupakis, F.; Ruzzo, A.; Cremolini, C.; Vincenzi, B.; Salvatore, L.; Santini, D.; Masi, G.; Stasi, I.; Canestrari, E.; Rulli, E.; Floriani, I.; Bencardino, K.; Galluccio, N.; Catalano, V.; Tonini, G.; Magnani, M.; Fontanini, G.; Basolo, F.; Falcone, A.; Graziano, F., KRAS codon 61,146 and BRAF mutations predict resistance to cetuximab plus irinotecan in KRAS codon 12 and 13 wild-type metastatic colorectal cancer. Br. J. Cancer, 2009, 101(4), 715-721.

[67] Di Nicolantonio, F.; Martini, M.; Molinari, F.; Sartore-Bianchi, A.; Arena, S.; Saletti, P.; De Dosso, S.; Mazzucchelli, L.; Frattini, M.; Siena, S.; Bardelli, A., Wild-type BRAF is required for response to panitumumab or cetuximab in metastatic colorectal cancer. J. Clin. Oncol., 2008, 26(35), 5705-5712.

[68] De Roock, W.; Claes, B.; Bernasconi, D.; De Schutter, J.; Biesmans, B.; Fountzilas, G.; Kalogeras, K. T.; Kotoula, V.; Papamichael, D.; Laurent-Puig, P.; Penault-Llorca, F.; Rougier, P.; Vincenzi, B.; Santini, D.; Tonini, G.; Cappuzzo, F.; Frattini, M.; Molinari, F.; Saletti, P.; De Dosso, S.; Martini, M.; Bardelli, A.; Siena, S.; Sartore-Bianchi, A.; Tabernero, J.; Macarulla, T.; Di Fiore, F.; Gangloff, A. O.; Ciardiello, F.; Pfeiffer, P.; Qvortrup, C.; Hansen, T. P.; Van Cutsem, E.; Piessevaux, H.; Lambrechts, D.; Delorenzi, M.; Tejpar, S., Effects of KRAS, BRAF, NRAS, and PIK3CA mutations on the efficacy of cetuximab plus chemotherapy in chemotherapy-refractory metastatic colorectal cancer: a retrospective consortium analysis. Lancet Oncol., 2010, 11(8), 753-762.

[69] Nassif, N. T.; Lobo, G. P.; Wu, X.; Henderson, C. J.; Morrison, C. D.; Eng, C.; Jalaludin, B.; Segelov, E., PTEN mutations are common in sporadic microsatellite stable colorectal cancer. Oncogene, 2004, 23(2), 617-628

[70] Loupakis, F.; Pollina, L.; Stasi, I.; Ruzzo, A.; Scartozzi, M.; Santini, D.; Masi, G.; Graziano, F.; Cremolini, C.; Rulli, E.; Canestrari, E.; Funel, N.; Schiavon, G.; Petrini, I.; Magnani, M.; Tonini, G.; Campani, D.; Floriani, I.; Cascinu, S.; Falcone, A., PTEN expression and KRAS mutations on primary tumors and metastases in the prediction of benefit from cetuximab plus irinotecan for patients with metastatic colorectal cancer. J. Clin. Oncol., 2009, 27(16), 2622-2629.

[71] Formica, V.; Massara, M. C.; Portarena, I.; Fiaschetti, V.; Grenga, I.; Del Vecchio Blanco, G.; Sileri, P.; Tosetto, L.; Skoulidis, F.; Pallone, F.; Roselli, M., Role of CA19.9 in predicting bevacizumab efficacy for metastatic colorectal cancer patients. Cancer Biomark., 2009, 5(4), 167-175.

[72] Saif, M. W.; Longo, W. L.; Israel, G., Correlation between rash and a positive drug response associated with bevacizumab in a patient with advanced colorectal cancer. Clin. Colorectal Cancer, 2008, 7 (2), 144-148.

[73] Tol, J.; Koopman, M.; Miller, M. C.; Tibbe, A.; Cats, A.; Creemers, G. J.; Vos, A. H.; Nagtegaal, I. D.; Terstappen, L. W.; Punt, C. J., Circulating tumour cells early predict progression-free and overall survival in advanced colorectal cancer patients treated with chemotherapy and targeted agents. Ann. Oncol., 2010, 21(5), 1006-1012.

[74] Brogan, I. J.; Khan, N.; Isaac, K.; Hutchinson, J. A.; Pravica, V.; Hutchinson, I. V., Novel polymorphisms in the promoter and 5' UTR regions of the human vascular endothelial growth factor gene. Hum. Immunol., 1999, 60(12), 1245-1249.

[75] Renner, W.; Kotschan, S.; Hoffmann, C.; Obermayer-Pietsch, B.; Pilger, E., A common $936 \mathrm{C} / \mathrm{T}$ mutation in the gene for vascular endothelial growth factor is associated with vascular endothelial growth factor plasma levels. J. Vasc. Res., 2000, 37(6), 443-448.

[76] Watson, C. J.; Webb, N. J.; Bottomley, M. J.; Brenchley, P. E., Identification of polymorphisms within the vascular endothelial growth factor (VEGF) gene: correlation with variation in VEGF protein production. Cytokine, 2000, 12(8), 1232-1235.
[77] Koukourakis, M. I.; Papazoglou, D.; Giatromanolaki, A.; Bougioukas, G.; Maltezos, E.; Sivridis, E., VEGF gene sequence variation defines VEGF gene expression status and angiogenic activity in non-small cell lung cancer. Lung Cancer, 2004, 46(3), 293-298.

[78] Krippl, P.; Langsenlehner, U.; Renner, W.; Yazdani-Biuki, B.; Wolf, G.; Wascher, T. C.; Paulweber, B.; Haas, J.; Samonigg, H., A common $936 \mathrm{C} / \mathrm{T}$ gene polymorphism of vascular endothelial growth factor is associated with decreased breast cancer risk. Int. $J$. Cancer, 2003, 106(4), 468-471.

[79] Shahbazi, M.; Fryer, A. A.; Pravica, V.; Brogan, I. J.; Ramsay, H M.; Hutchinson, I. V.; Harden, P. N., Vascular endothelial growth factor gene polymorphisms are associated with acute renal allograft rejection. J. Am. Soc. Nephrol., 2002, 13(1), 260-264.

[80] Stevens, A.; Soden, J.; Brenchley, P. E.; Ralph, S.; Ray, D. W., Haplotype analysis of the polymorphic human vascular endothelial growth factor gene promoter. Cancer Res., 2003, 63(4), 812-816.

[81] Awata, T.; Inoue, K.; Kurihara, S.; Ohkubo, T.; Watanabe, M.; Inukai, K.; Inoue, I.; Katayama, S., A common polymorphism in the 5'-untranslated region of the VEGF gene is associated with diabetic retinopathy in type 2 diabetes. Diabetes, 2002, 51(5), 16351639.

[82] Howell, W. M.; Bateman, A. C.; Turner, S. J.; Collins, A.; Theaker, J. M., Influence of vascular endothelial growth factor single nucleotide polymorphisms on tumour development in cutaneous malignant melanoma. Genes Immun., 2002, 3(4), 229-232.

[83] Jin, Q.; Hemminki, K.; Enquist, K.; Lenner, P.; Grzybowska, E.; Klaes, R.; Henriksson, R.; Chen, B.; Pamula, J.; Pekala, W.; Zientek, H.; Rogozinska-Szczepka, J.; Utracka-Hutka, B.; Hallmans, G.; Forsti, A., Vascular endothelial growth factor polymorphisms in relation to breast cancer development and prognosis. Clin. Cancer Res., 2005, 11(10), 3647-3653.

[84] Lee, S. J.; Lee, S. Y.; Jeon, H. S.; Park, S. H.; Jang, J. S.; Lee, G. Y.; Son, J. W.; Kim, C. H.; Lee, W. K.; Kam, S.; Park, R. W.; Park, T. I.; Kang, Y. M.; Kim, I. S.; Jung, T. H.; Park, J. Y., Vascular endothelial growth factor gene polymorphisms and risk of primary lung cancer. Cancer Epidemiol, Biomarkers Prev., 2005, 14(3), $571-575$.

[85] Lu, H.; Shu, X. O.; Cui, Y.; Kataoka, N.; Wen, W.; Cai, Q.; Ruan, Z. X.; Gao, Y. T.; Zheng, W., Association of genetic polymorphisms in the VEGF gene with breast cancer survival. Cancer Res. 2005, 65(12), 5015-5019.

[86] Kariyazono, H.; Ohno, T.; Khajoee, V.; Ihara, K.; Kusuhara, K.; Kinukawa, N.; Mizuno, Y.; Hara, T., Association of vascular endothelial growth factor (VEGF) and VEGF receptor gene polymorphisms with coronary artery lesions of Kawasaki disease. Pediatr. Res., 2004, 56(6), 953-959.

[87] Pander, J.; Wessels, J. A.; Gelderblom, H.; van der Straaten, T.; Punt, C. J.; Guchelaar, H. J., Pharmacogenetic interaction analysis for the efficacy of systemic treatment in metastatic colorectal cancer. Ann. Oncol., 2010.

[88] Yalcin, S., The increasing role of pharmacogenetics in the treatment of gastrointestinal cancers. Gastrointest. Cancer Res., 2009 , 3(5), 197-203.

[89] Schneider, B. P.; Wang, M.; Radovich, M.; Sledge, G. W.; Badve, S.; Thor, A.; Flockhart, D. A.; Hancock, B.; Davidson, N.; Gralow, J.; Dickler, M.; Perez, E. A.; Cobleigh, M.; Shenkier, T.; Edgerton, S.; Miller, K. D., Association of vascular endothelial growth factor and vascular endothelial growth factor receptor-2 genetic polymorphisms with outcome in a trial of paclitaxel compared with paclitaxel plus bevacizumab in advanced breast cancer: ECOG 2100. $J$. Clin. Oncol., 2008, 26(28), 4672-4678.

[90] Burstein, H. J.; Chen, Y. H.; Parker, L. M.; Savoie, J.; Younger, J.; Kuter, I.; Ryan, P. D.; Garber, J. E.; Chen, H.; Campos, S. M. Shulman, L. N.; Harris, L. N.; Gelman, R.; Winer, E. P., VEGF as a marker for outcome among advanced breast cancer patients receiving anti-VEGF therapy with bevacizumab and vinorelbine chemotherapy. Clin. Cancer Res., 2008, 14(23), 7871-7877.

[91] Solomon, B. M.; Jatoi, A., Rash from EGFR inhibitors: opportunities and challenges for palliation. Curr. Oncol. Rep., 2008, 10(4), 304-308.

[92] Jatoi, A.; Nguyen, P. L., Do patients die from rashes from epidermal growth factor receptor inhibitors? A systematic review to help counsel patients about holding therapy. Oncologist, 2008, 13(11), 1201-1204.

[93] Jatoi, A.; Rowland, K.; Sloan, J. A.; Gross, H. M.; Fishkin, P. A Kahanic, S. P.; Novotny, P. J.; Schaefer, P. L.; Johnson, D. B.; 
Tschetter, L. K.; Loprinzi, C. L., Tetracycline to prevent epidermal growth factor receptor inhibitor-induced skin rashes: results of a placebo-controlled trial from the North Central Cancer Treatment Group (N03CB). Cancer, 2008, 113(4), 847-853.

[94] Scope, A.; Agero, A. L.; Dusza, S. W.; Myskowski, P. L.; Lieb, J. A.; Saltz, L.; Kemeny, N. E.; Halpern, A. C., Randomized doubleblind trial of prophylactic oral minocycline and topical tazarotene for cetuximab-associated acne-like eruption. J. Clin. Oncol., 2007, 25(34), 5390-5396.

[95] Reenstra, W. R.; Yaar, M.; Gilchrest, B. A., Aging affects epidermal growth factor receptor phosphorylation and traffic kinetics. Exp. Cell Res., 1996, 227(2), 252-255.

[96] Migliaccio, A.; Castoria, G.; Di Domenico, M.; Ciociola, A.; Lombardi, M.; De Falco, A.; Nanayakkara, M.; Bottero, D.; De Stasio, R.; Varricchio, L.; Auricchio, F., Crosstalk between EGFR and extranuclear steroid receptors. Ann. N. Y. Acad. Sci., 2006, $1089,194-200$.
[97] Lai, S. E.; Minnelly, L.; O'Keeffe, P. In Influence of skin color in the development of erlotinib-induced rash: a report from the SERIES clinic, ASCO Annual Meeting, 2007; 2007.

[98] Wacker, B.; Nagrani, T.; Weinberg, J.; Witt, K.; Clark, G.; Cagnoni, P. J., Correlation between development of rash and efficacy in patients treated with the epidermal growth factor receptor tyrosine kinase inhibitor erlotinib in two large phase III studies. Clin. Cancer Res., 2007, 13(13), 3913-3921.

[99] Rudin, C. M.; Liu, W.; Desai, A.; Karrison, T.; Jiang, X.; Janisch, L.; Das, S.; Ramirez, J.; Poonkuzhali, B.; Schuetz, E.; Fackenthal, D. L.; Chen, P.; Armstrong, D. K.; Brahmer, J. R.; Fleming, G. F.; Vokes, E. E.; Carducci, M. A.; Ratain, M. J., Pharmacogenomic and pharmacokinetic determinants of erlotinib toxicity. J. Clin. Oncol., 2008, 26(7), 1119-1127.

[100] Jatoi, A.; Green, E. M.; Rowland, K. M., Jr.; Sargent, D. J.; Alberts, S. R., Clinical predictors of severe cetuximab-induced rash: observations from 933 patients enrolled in north central cancer treatment group study N0147. Oncology, 2009, 77(2), 120-123. 